\title{
Oncology services in corona times: a flash interview among German cancer patients and their physicians
}

\author{
Jens Büntzel ${ }^{1}\left[\right.$ D Michael Klein $^{2} \cdot$ Christian Keinki $^{2} \cdot$ Stefanie Walter $^{3} \cdot$ Judith Büntzel $^{4} \cdot$ Jutta Hübner $^{2}$
}

Received: 23 April 2020 / Accepted: 6 May 2020 / Published online: 15 May 2020

(c) Springer-Verlag GmbH Germany, part of Springer Nature 2020

\begin{abstract}
Objective Public discussion and health-care systems worldwide have been focusing on the COVID-19 pandemic. Does it have an impact on cancer care today?

Materials and methods The PRIO ("Prevention and Integrative Oncology") Working Group (German Cancer Society) has initiated an online survey for physicians, medical staff and patients on April 16, 2020. Between April 16 and April 19, 47 doctors and 146 patients filled in the questionnaires. The survey is ongoing. We present the first data.

Results A majority of German patients (76\%) and physicians (71\%) report moderate or high restriction in their daily life. A minority (patients $25 \%$, physicians $13 \%$ ) was not worried that necessary treatments or diagnostics were restricted. Organizing cancer care needs more time and efforts for $56 \%$ of all reporting doctors. $98 \%$ of all oncologists think that restriction of family visits has a negative impact on the mental health of cancer patients. Half of all participants (patients $43 \%$, physicians 47\%) expect negative consequences on the physical status of our patients. Patients feel the existing emotional stress in $34 \%$ of their physicians. 52\% of physicians fear mental and/or physical longtime consequences for themselves.

Conclusion There is a high level of mental and physical stress triggered by the present COVID-19 management. After only a few weeks, human resources are limited. They will be the most important key for further health-care services for patients with cancer and other chronic diseases.
\end{abstract}

Dear editor,

Starting from the 16th of March 2020, the German government has decreed that all unnecessary medical interventions, contacts and treatments should be deferred to a later (undefined) date, if it was medically justifiable to do so. According to the governmental decree, the German health-care systems' focus shifted from usual care to increasing intensive care unit (ICU) capacities for ventilation. Human resources were to be transferred to infectiology wards and ICUs. Already at

Jens Büntzel

jens.buentzel@shk-ndh.de

1 Department of Otolaryngology, Palliative Medicine, Südharz-Klinikum Nordhausen, Dr.-Robert-Koch-Str. 39, 99734 Nordhausen, Germany

2 Department of Internal Medicine II, University Hospital Jena, Jena, Germany

3 German Federal Association of Throat Cancer Patients, Bonn, Germany

4 Department of Hematology and Medical Oncology, University Hospital Göttingen, Göttingen, Germany this date, some Federal States have discussed banning family members from visiting inpatients and the elderly in nursing homes (Ärzteblatt DÄG Redaktion Deutsches 2020). The latter did also become common practice soon (NDR Coronavirus in SH: Besuchsverbot in Pflegeheimen und Kliniken 2020). However, what does this change mean to millions of vulnerable patients suffering from chronic diseases and/or cancer? According to the Cancer Register of the German Robert-Koch-Institute, German health services had $>3.5$ million outpatients and $>1.2$ million inpatients contacts in 2013 (Krebs 2020). Breaking these numbers down, German health-care providers have $>390,000$ in- and outpatient contacts per month. It seems challenging to near impossible to provide this standard of care while the health system tries to weather the corona pandemic. The research teams' "communication" and "spirituality" of the Working Group Prevention and Integrative Oncology_-German Cancer Society therefore launched an online questionnaire assessing how treating physicians and cancer patients perceive the current situation.

Methods: A questionnaire was designed for each group. The survey was anonymous, metric data were only assessed 
concerning Federal State (physician, patients), cancer entity (patients) and whether physicians were (1) mainly involved in the care of in- and/or outpatients and (2) in contact with patients suffering from COVID-19. Scale questions were mainly used to assess the impact and consequences of the German measures of COVID-19 management for patients (physicians' and patients' questionnaire). In four cases, simple or multiple-choice questions were used to determine the influence of COVID-19 on the treating physician's life (physicians' questionnaire). One question used the allegory of a thermometer to capture the current emotional status of the treating medical staff (both questionnaires, scale question). The online tool https://soscisurvey.de was used to program and distribute the online questionnaire. The online survey was started on the 16th of April 2020. Data of the flash poll of calendar week 16 was downloaded on Sunday 19th of April 2020, 18:00 CET. Pivot shift tables and percentages were calculated using Microsoft Excel. The link to the questionnaire was distributed among the members of the participating associations only (professionals: PRIO, patients: Haus der Krebs-Selbsthilfe).

Results: During the initial flash poll (16-19 April 2020), 146 patients and 47 physicians completed the online questionnaire. Mostly patients (50\%) and physicians (53\%) from Southern Germany (Bavaria, Baden-Würtemberg) and North Rhine-Westphalia participated. $54 \%$ of the patients were older than 60 years and $24 \%$ of all physicians were directly involved in treating patients suffering from COVID-19. The majority of physicians (76\%) and patients (71\%) felt moderately to highly restricted in their daily life; and $71 \%$ of all patients questioned were very or moderately irritated by the information distributed by the media (physicians: 47\%). 37\% of treating oncologists describe a highly increased amount of their patients' questions. Only a minority of both stakeholder groups (physicians: $13 \%$, patients: $25 \%$ ) was not worried that necessary treatments or diagnostics were restricted. Seventy-four percent of oncologists require more time to convince patients to undergo curative or palliative treatment. Organizing cancer care during the corona pandemic requires more resources and is more difficult for $56 \%$ of the treating physicians; however, 39\% state that they and their team are able to cope. $98 \%$ of all physicians estimate that banning visits of family members for inpatients has a moderate to highly negative impact on the patients' recovery or healing process. $48 \%$ of the patients staying at the hospital during the visit ban and $84 \%$ of the patients not requiring care in hospital voiced similar concerns. Only $2 \%$ of the physicians and $14 \%$ of the patients believe that the current crisis will not have any impact on the mental or spiritual health (e.g., sleeping disorders, depressions, anxiety disorders) of the patients. More than $40 \%$ of both groups (physicians: $47 \%$, patients $43 \%$ ) expect a long-term impact on physical health. Seventy-three percent of the participating patients indicated that they were already suffering from the physical impact of the lockdown (e.g., loss of muscle mass, fatigue, loss of appetite). However, $64 \%$ of all patients describe the possibility for physical training as very good. Considering the physicians' ratings of the impact of the crisis on their own mental and physical health, only the minority (48\%) of the oncologists do not fear any impact. In contrast, there are existing fear rates for mental health $21 \%$, for physical health $7 \%$, and for physical as well as mental health $24 \%$. Additionally, $17 \%$ of doctors fear financial consequences and $40 \%$ about getting infected by the SARS-CoV-2 virus.

Regarding patients, a vast majority of physicians report that their patients feel insecure $(71 \%)$ and $21 \%$ describe patients as full of fear and isolating themselves. Moreover, a third $(33 \%)$ of the physicians themselves feel emotionally stressed or burned out. Vice versa, $34 \%$ of the patients describe the medical staff as emotionally stressed or burned out.

Figure 1 summarizes the different data about mental and physical health of the medical staff, because this will be the key resource for a continued high-level cancer care in the future.

Discussion: This first data analysis represents a unique view into the situation of patients with cancer and the attending physicians. The emotional answers are unfiltered by time or social/scientific impact. Despite their different points of view, all participants have given very similar answers. The key messages of this flash interview project are.

- a high level of mental and physical stress has been triggered by the COVID-19 management on the German oncology system,

- a strong pool of mental and physical strength is needed to overcome this situation and to uphold the ongoing treatments and programs for cancer patients,

- a deep uncertainty is felt by physicians and their patients related to the information policy of the German government or official epidemiological statements given by the authorities,

- after only a few weeks, nearly a third of health-care professionals have reached their individual limits.

While there seems to be a high level of resilience in both groups, this resilience is not without limits. To maintain an adequate care for cancer patients, there is a high need for further resources in time, manpower and money (Diefenbach et al. 2009). Most probably, the same will be the case in other patient groups with chronic and/or life-threatening diseases.

While physicians and nurses strive to provide optimal care and physicians try to fill in down-breaking resources and socalled system-relevant services by financial resources, the rising ethical questions and problems make it quite clear 
Fig. 1 Mental and/or physical health of physicians (self perception)

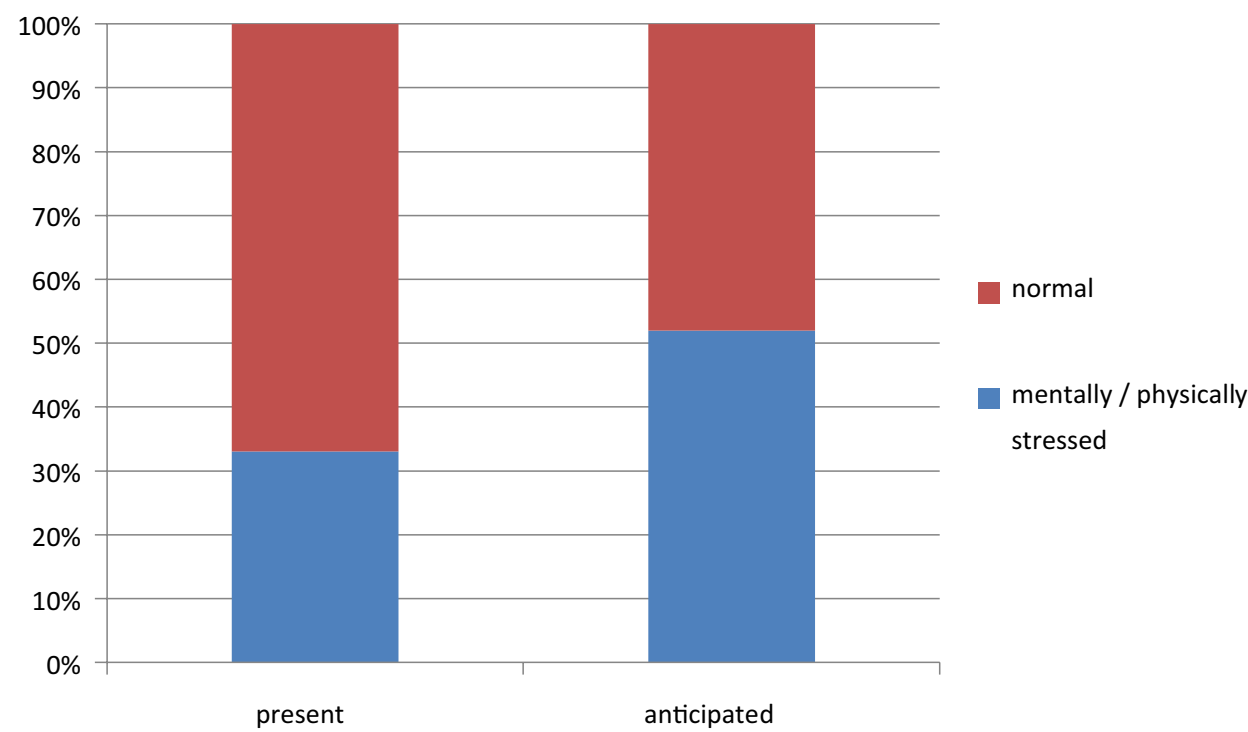

that the actual decision is no longer one of health versus economics. Furthermore, we anticipate a competition of different patient groups for rare resources in the health care and social system, namely trained and experienced physicians and nurses.

For this reason, a wider view on the epidemic is urgently needed including experts from all medical disciplines. An open discussion of the pros and cons of different decisions and their consequences must include the weighing of ethical aspects and fundamental rights. To keep acceptance in the society high, transparent and evidence-based information of the citizens and a balanced, open public discourse will be necessary. Producing fear and panic among patients and professionals as we have had to register in the past (Das interne Strategiepapier des Innenministeriums zur CoronaPandemielabgeordnetenwatch.de 2020) will further exhaust and rapidly reduce human resources urgently needed. We plan to continue this survey through the whole pandemic to document the view of the moment as well as the changing burden of the pandemic on the health-care system. Each colleague is invited to take part in this project. Please follow the links presented at the website of our study group (https ://prio-dkg.de/).

Funding There was no funding of this study.

\section{Compliance with ethical standards:}

Conflict of interest All authors declare that they have no conflict of interest.
Ethical approval All procedures performed in studies involving human participants were in accordance with the ethical standards of the institutional and/or national research committee and with the 1964 Helsinki Declaration and its later amendments or comparable ethical standards. The research was approved by the ethics committee of Jena University Hospital.

\section{References}

Ärzteblatt DÄG Redaktion Deutsches (2020) Corona: Krankenhäuser sollen ab Montag alle planbaren Eingriffe. In: Dtsch. Ärztebl. https://www.aerzteblatt.de/nachrichten/111034/Corona-Krank enhaeuser-sollen-ab-Montag-alle-planbaren-Eingriffe-verschiebe n. Accessed 21 Apr 2020

NDR Coronavirus in SH: Besuchsverbot in Pflegeheimen und Kliniken (2020) /nachrichten/schleswig-holstein/coronavirus/Coronavirus-in-SH-Besuchsverbot-in-Pflegeheimen-und-Kliniken, besuchsverbot102.html. Accessed 21 Apr 2020

Krebs (2020) Versorgung von Menschen mit Krebs. https://www.krebs daten.de/Krebs/DE/Content/Publikationen/Krebsgeschehen/Verso rgung/Kapitel3_Versorgung.pdf;jsessionid=F41B27763406C7E 99C0340DDA05C6668.2_cid372?__blob=publicationFile. Accessed 21 Apr 2020

Diefenbach M, Turner G, Carpenter KM et al (2009) Cancer and patient-physician communication. J Health Commun 14:57-65. https://doi.org/10.1080/10810730902814079

Das interne Strategiepapier des Innenministeriums zur CoronaPandemielabgeordnetenwatch.de (2020) https://www.abgeordnet enwatch.de/blog/informationsfreiheit/das-interne-strategiepapier -des-innenministeriums-zur-corona-pandemie. Accessed $21 \mathrm{Apr}$ 2020

Publisher's Note Springer Nature remains neutral with regard to jurisdictional claims in published maps and institutional affiliations. 